\title{
الإشهار التجاري من بعض زوايا القاتون العام
}

\section{د. نجيب بن عمر عوينات \\ مساعد في القانون العام بجامعة تونئ

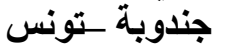

نظر الأهمية الخطابة في تدبير شُؤون الناس فقد إعتبرها أرسطو الأداة الأساسية في توجيه دفة

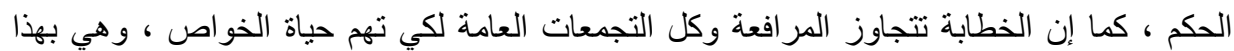

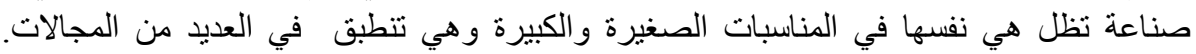

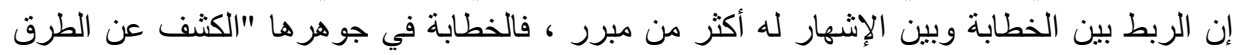

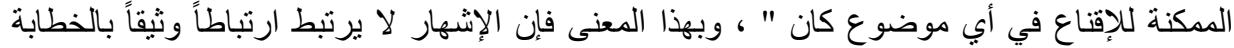
وحسب بل يرتبط بخطابة الأهو اء أو النوازع.

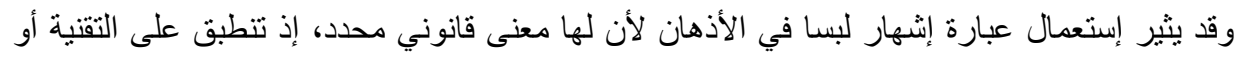

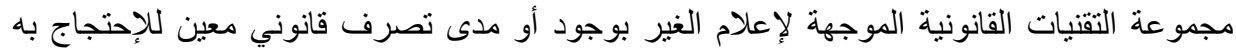

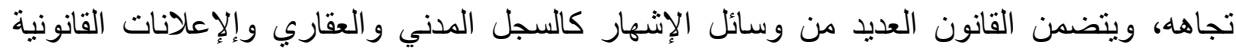

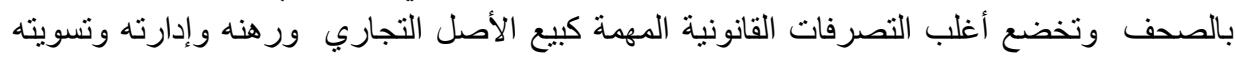
وتكوين الثركات التجارية إلز اما للإشهار (1).

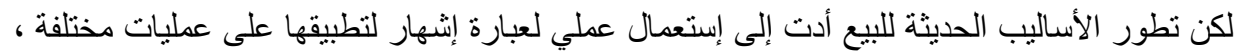

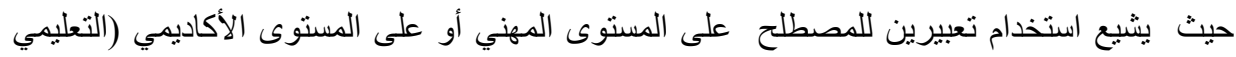

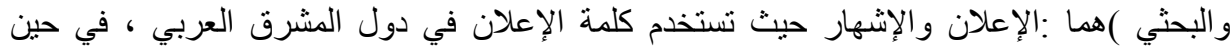

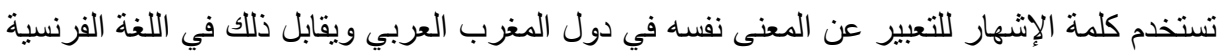

(Lublicity) أوفي الإنجليزية (Advertising). (La Publicité),

ولقد ورد تعريف الإشهار في قاموس LAROUSSE كما يلي " يعرّف الإثهار بأنّه مجموع الوسائل

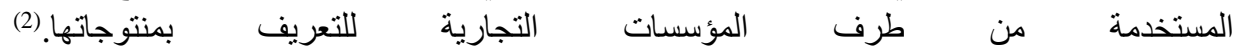

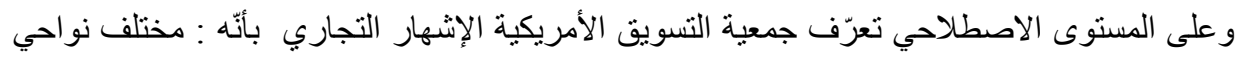

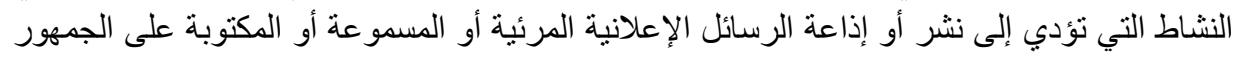

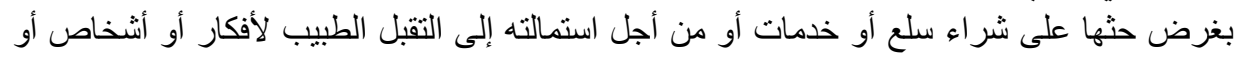

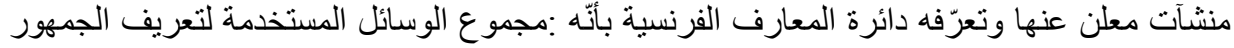

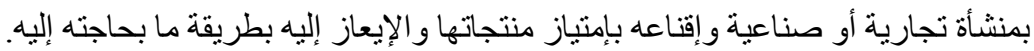


و في إطار تقريب المنتجات و الخدمات من المستهللك و تر غيبه في إقتنائها ظهر ما يسمى بالإشهار

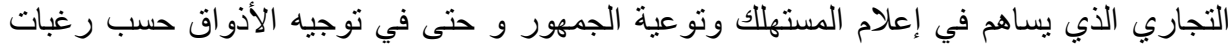

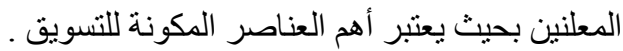

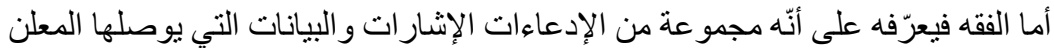

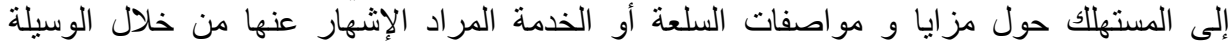

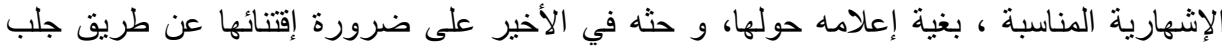

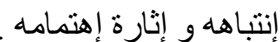

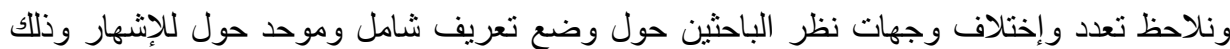

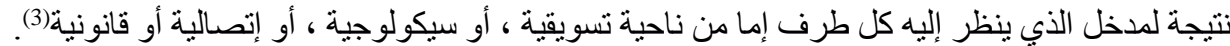

و قد عرّف المشرع التونسي الإنشهار التجاري في الفصل الأول من القانون عدد 22 لسنة 1971

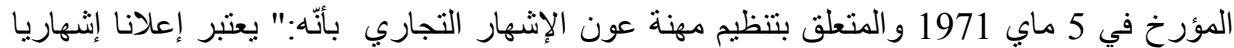

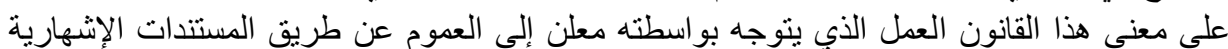

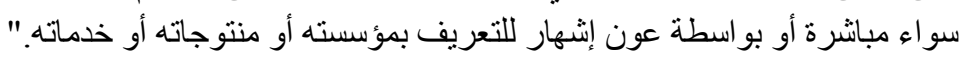

أما الفصل 35 من القانون عدد 40 لسنة 1998 المؤرخ في 2 جوان 1998 المتعلق بطرق البيع

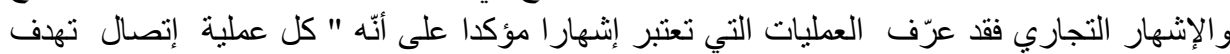
بصفة مباثرة أو غير مبانرة إلى تتمية بيع منتوجات أو إسداء خدمات مهما كان المكان أو وسائل

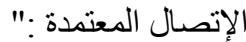

إن السؤال المطروح لماذا أعاد المشرع تعريف الإشهار ؟ خاصة أن التعريف الأول لازال ساري

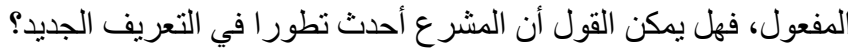
وفي الحقيقة لا يمكن فهم حقيقة الإشهار التجاري إلا بوضعه في سياقين إثثين: الأول :هو سياق إزدهار الرأسمالية وتطور الإنتاج بحيث أصبح يفيض عن الحاجات ، ومع التطو التطور

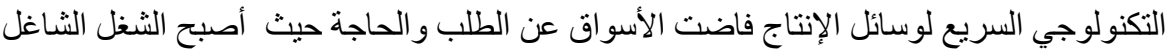

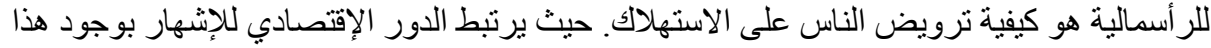

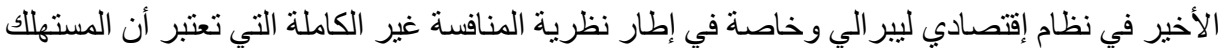

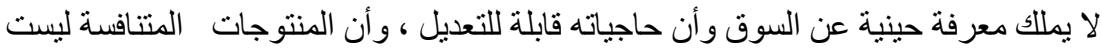

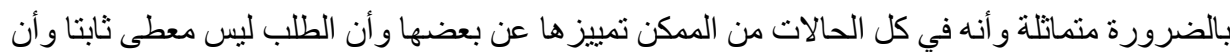

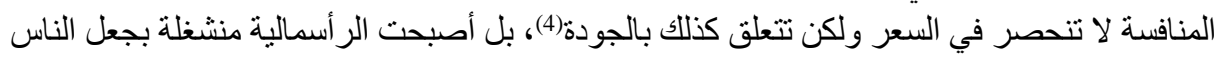

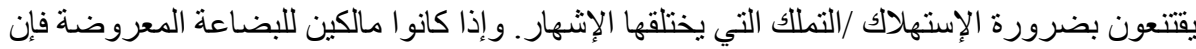

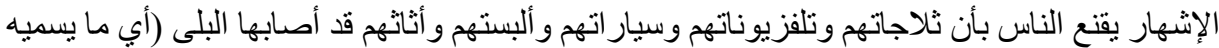

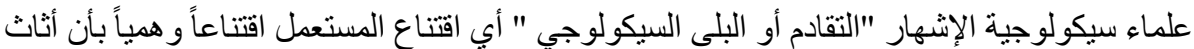

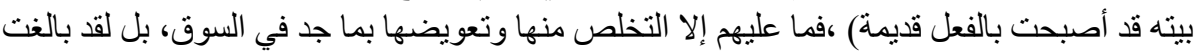

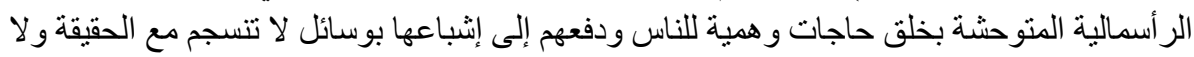




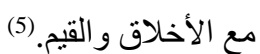

الثاني : تطور وسائل الإتصال الر اديو و التلفزيون و و الصحافة و الملصقات في الأماكن العمومية و أخيراً

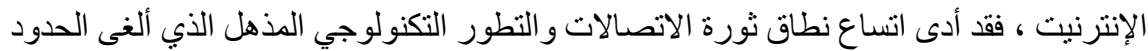

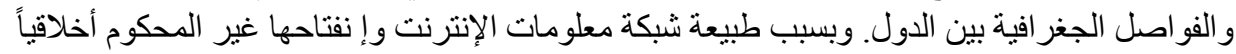

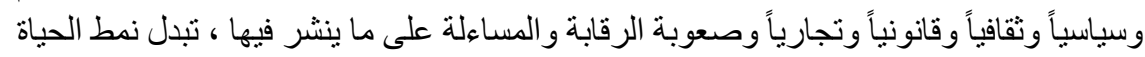

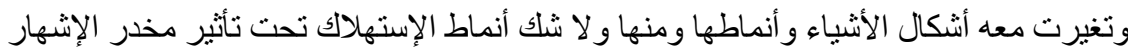

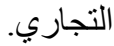

و الواقع أن أهم ما يميز وسائل الاتصال المعاصرة هو توجهها إلى جمهور غير محدد، و لهذا أصبح

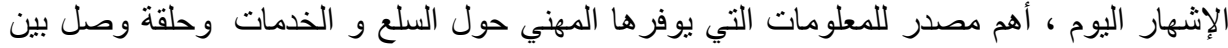

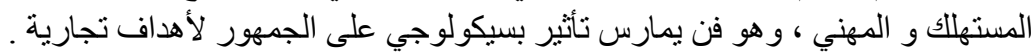

و إن دراستتا لموضوع الإشهار التجاري من بعض زوايا القانون العام ستركز بالأساس على نقطتين

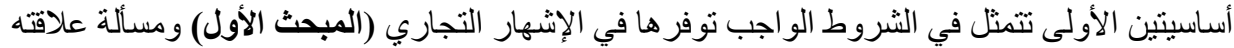
بحقوق الإنسان (المبحث الثاني). المبحث الأول : الثروط الواجب توفرها في الإثهار التجاري:

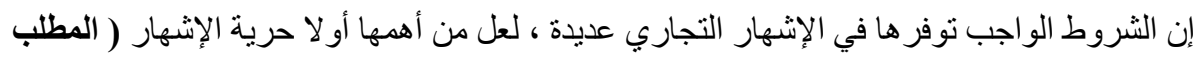

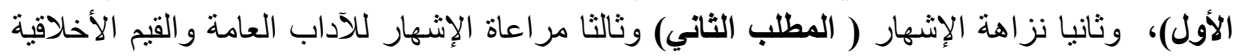
و البعد الجمالي للنظام العام (المطلب الثالث). المطلب الأول : مرية الإشهار

إن المقصود بحرية الإشهار أن كل شخص حر في اللجوء إلى تقنيات الإتصال لتطوير مصالحه

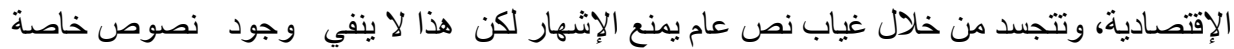

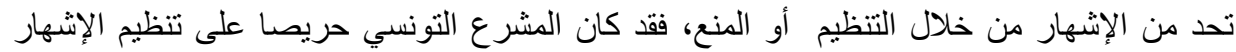

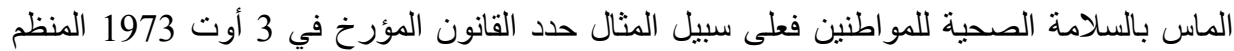

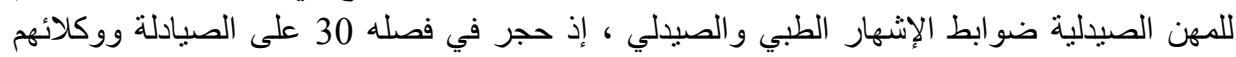

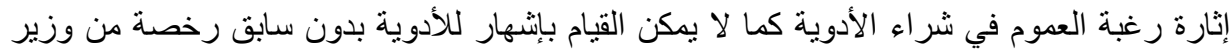

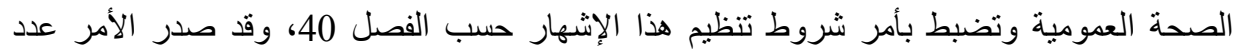

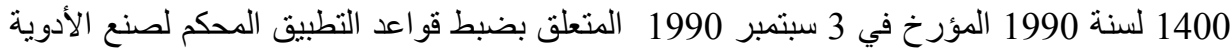

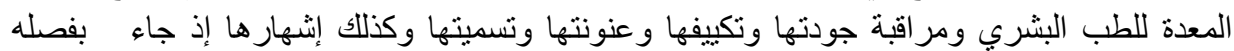

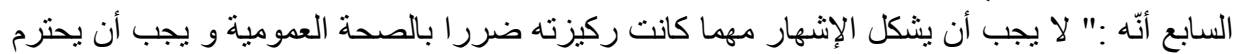

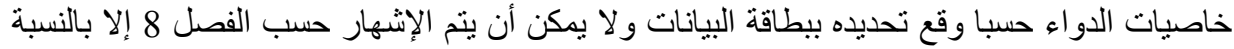

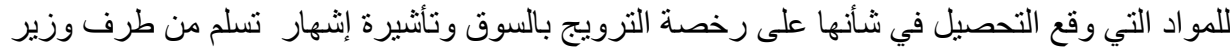

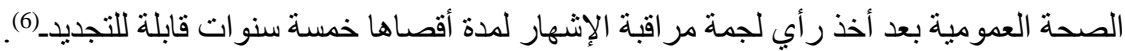


و ينص الفصل 36 من القانون التونسي عدد 40 لسنة 1998 المؤرخ في 2 جوان 1998 المنعلق بتقنيات البيع و الإشهار التجاري" تمنع كل عملية إثشار تنتلق بـ:

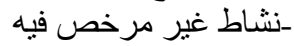

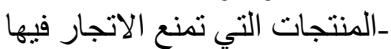

ـالمنتجات غير المتوفرة بالسوق خلال حملة الإشهار

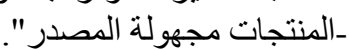

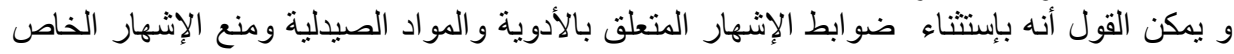

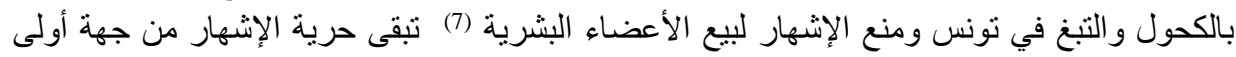

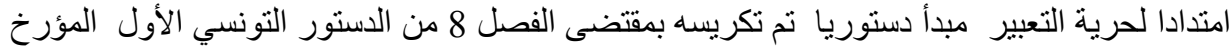

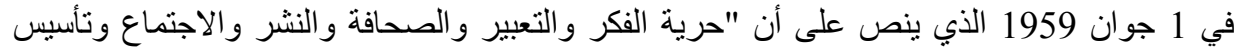

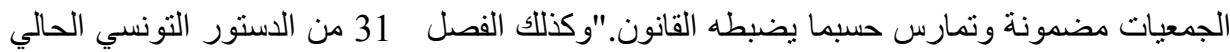

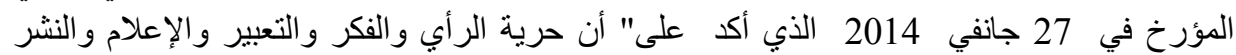

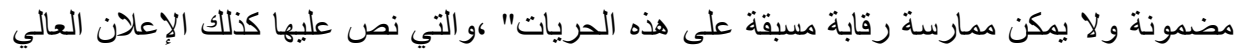

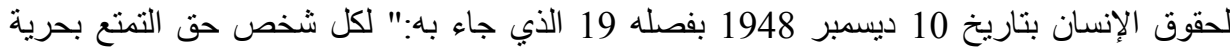

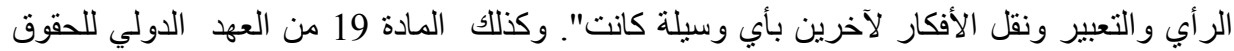

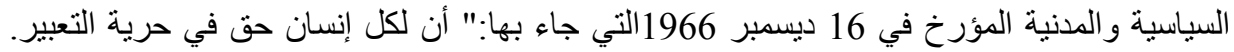

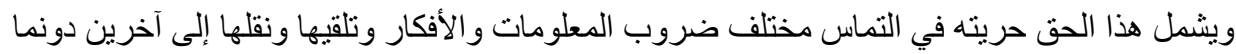
إعنبار للحدود ، سو اء على شكل مكتوب أو مطبو ع أو في قالب فني أو بأية وسيلة أخرى يختار ها."

ومن جهة ثانية تعتبر حرية الإشهار نتيجة لمبدأ حرية الصناعة والتجارة الذي برز في القرن الثامن

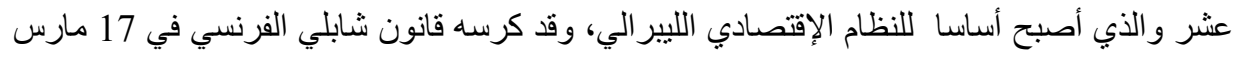

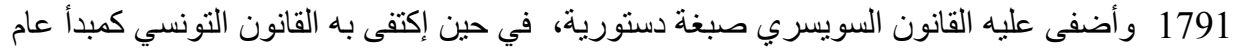

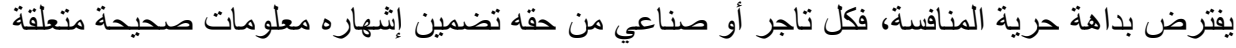
بشخصه أو منتوجه من أجل جلب الزبائن لأن الحرفاء عنصر ذا ذا أهمية قصوى في النشاط المهن المهني عليه

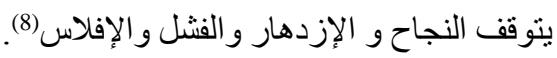

وقد مثلت حرية الصناعة والتجارة مستتدا أساسيا للمحكمة الإدارية في تونس لإلغاء قرار بلدي مؤرخ

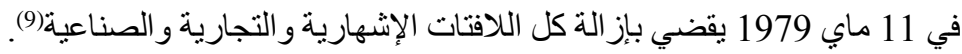

وتتأكد حرية الإشهار كنتاج لحرية الصناعة والتجارة من خلال الفصل 303 من المجلة

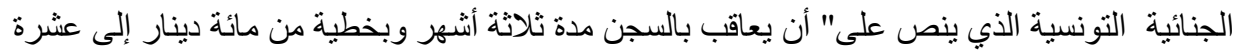

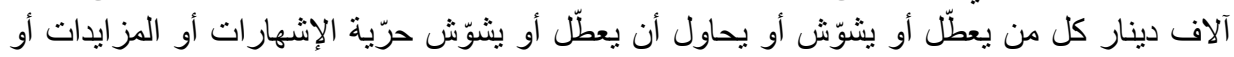

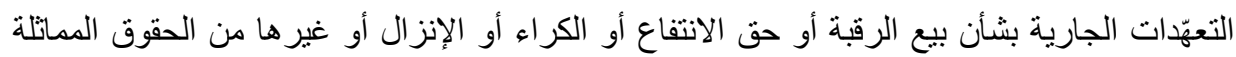

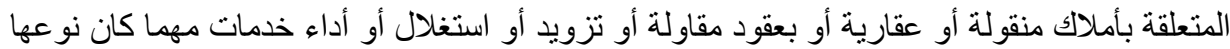

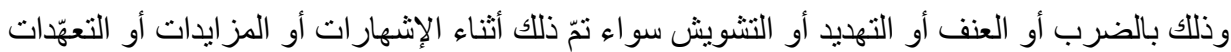

أو قبلها.

ويستوجب نفس العقاب المقرّر بالفقرة المتقدّة كل من يثني أو يحاول إثناء الراغبين في المز ايدة بعطايا أو وعود أو يقبل مثل هذه العطايا أو الوعود. 
ويستوجب أيضا نفس العقوبات كل من يعرض مجددا للمز ايدة، دون مشاركة السلطة ذات النظر ، أثياء كانت موضو ع مناقصة عمومية أو يثار لك في المز ايدة فيها.".

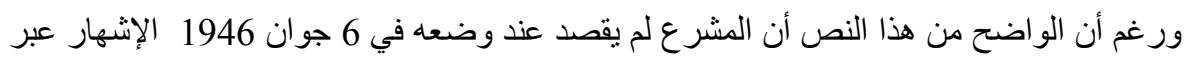

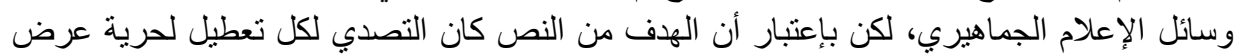

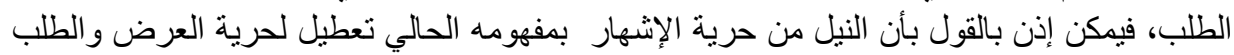
ويجوز بالتالي تطبيق الفصل على الإشهار عبر وسائل الإعلام الجماهيري(10).

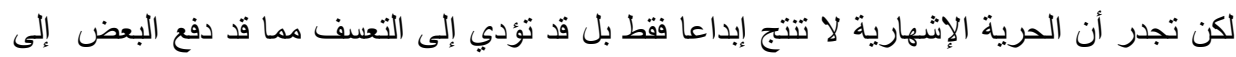

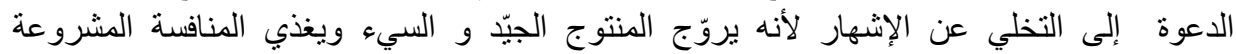

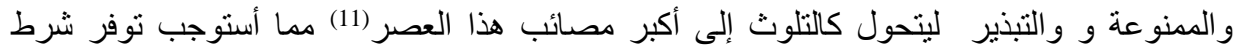

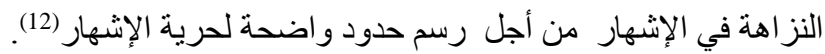

\section{المطلب الثاني : تزاهة الإشهار}

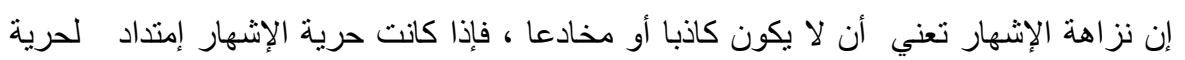

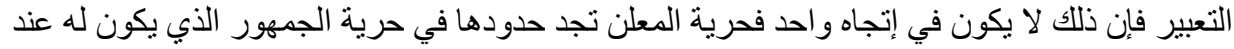

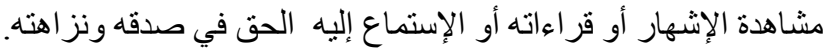

إن الكذب في الإشهار مسألة لا تتعلق بالقانون فقط بل بالدين والأخلاق قبل ذلك، إذ حث الإسلام على في

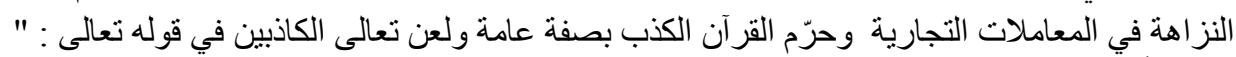

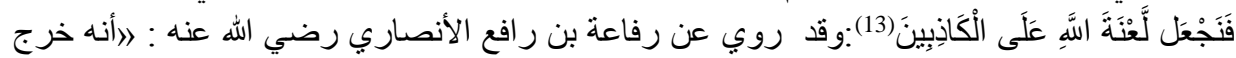

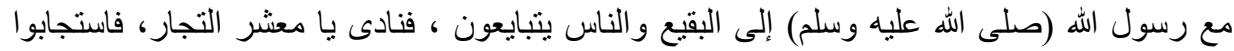

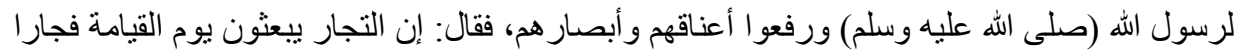

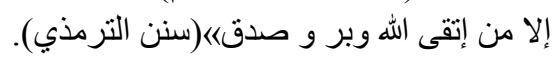

وقد روي عن أبي ذر رضي الله عنه عنه أن النبي (صلى الله عليه وسلم) قال: اخثلاثة لا يكلمهم الله يوم

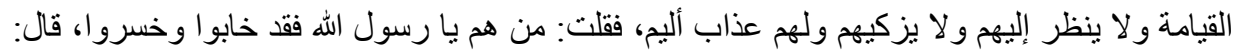

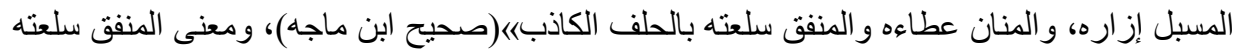

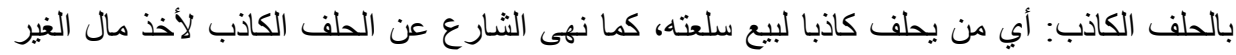

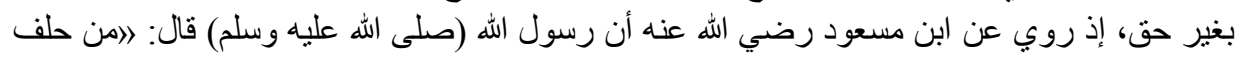

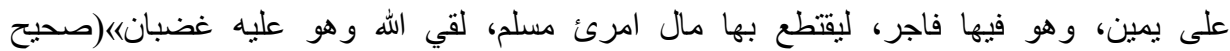

البخاري)(14) ، مما يدل على طلب النشارع الصدق من المتعاملين و البر في معاملاتهم مع غير هم (15).

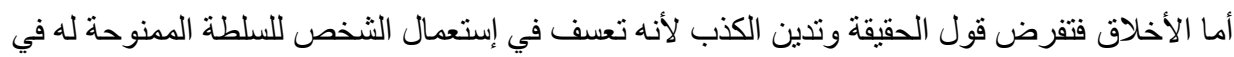

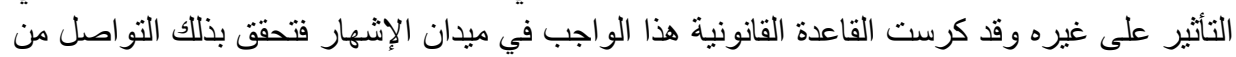

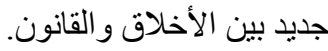


ونظر العدم كفاية النصوص العامة المدنية والجز ائية التي تجرّم الإنشهار الكاذب أصدر المشر ع التونسي

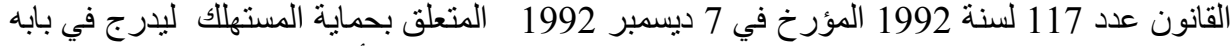

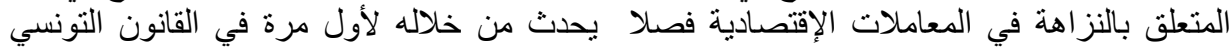

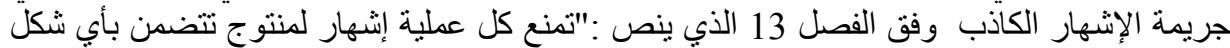

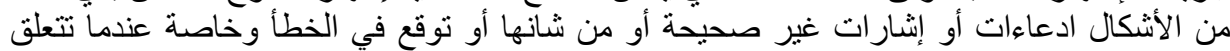

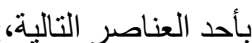

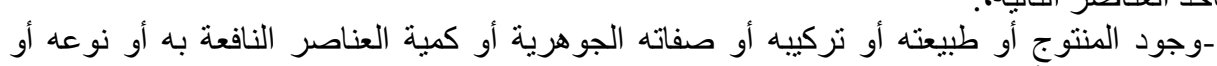

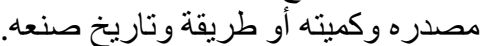

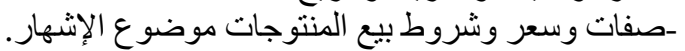

- مروط الاستعمال و النتائج المنتظرة.

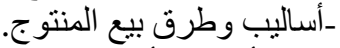
ـ الهوية أو صفة أو كفاءة المعلن.

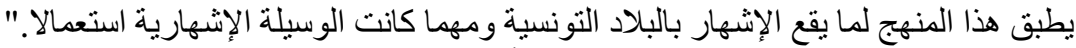

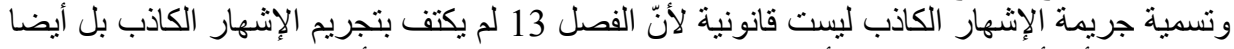

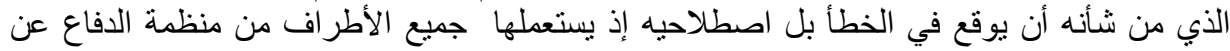

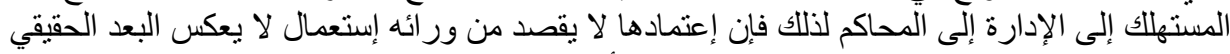

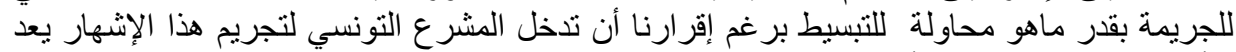

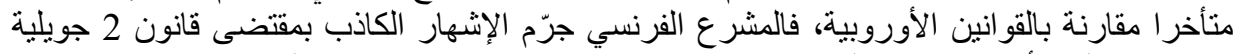

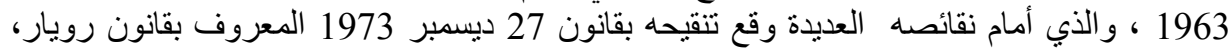

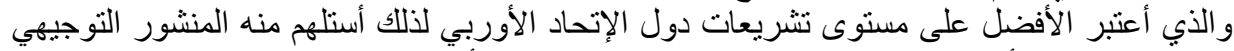

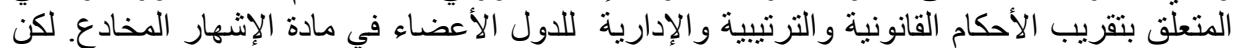

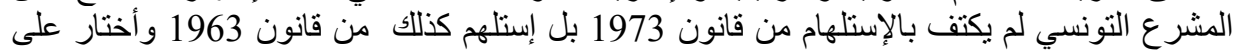

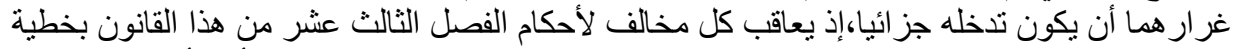

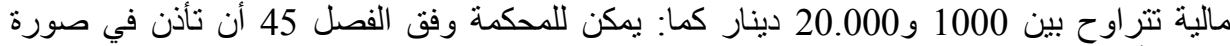

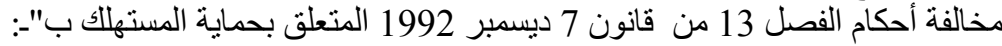

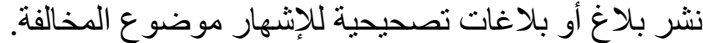

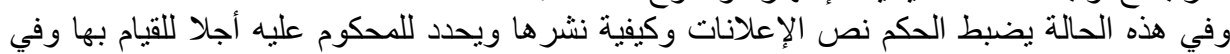

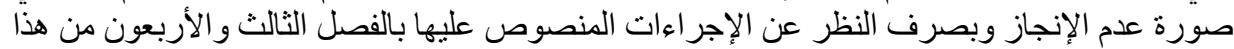
القانون يقع تتفيذ نشر الإعلانات على الإنى نفقة المحكوم عليه -إيقاف الإشهار أو سحبه أو تشطيبه."

ورغم أننا في تونس لسنا مجتمعا إستهلاكيا(16) ، و مازلنا شعبا يبحث عن حلول لقضايا أكثر مصيرية

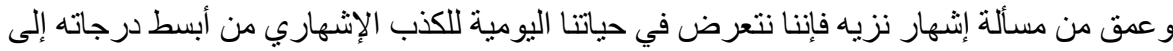

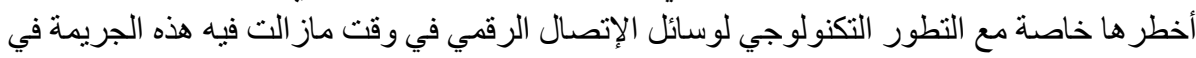

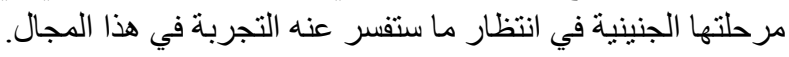

المطلب الثالث : تقيد الإشهار التجاري بمراعاة الآداب العامة والقيم الأخلاقية والبعد الجمالي للنظام 


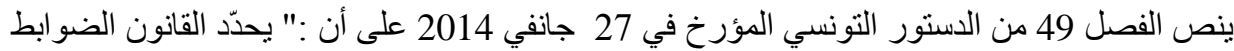

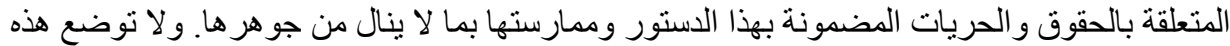

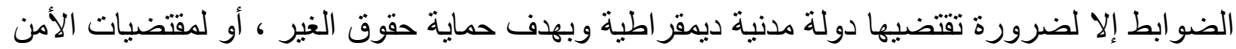

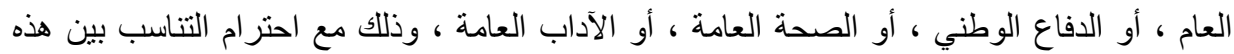

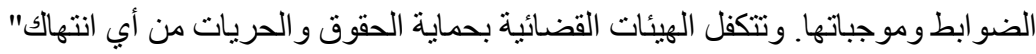

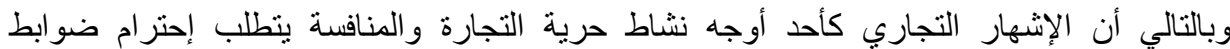

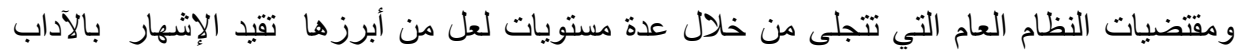

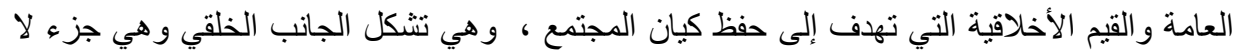

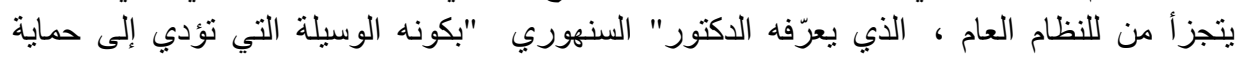
المصالح العليا العامة سياسية أو إجتماعية أو إقتصادية أو أخلاقية أو دينية تتعلق بنظام المجتمع الأعلى الميلى

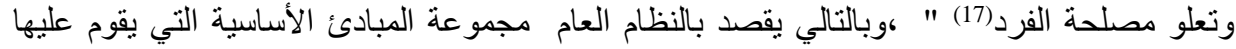

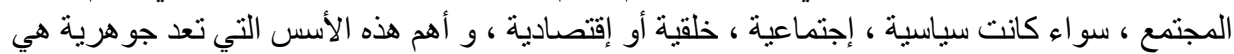

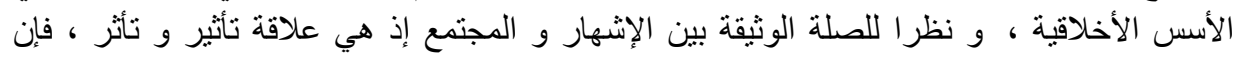

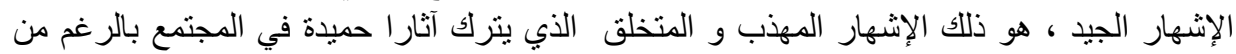

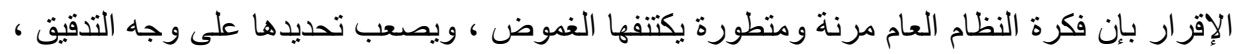

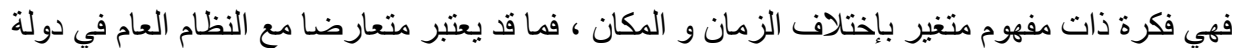

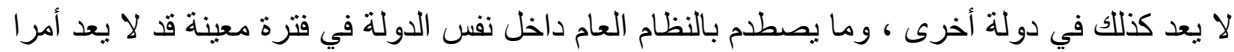
منافيا لهذه الفكرة في وقت دولت آخر ، (18).

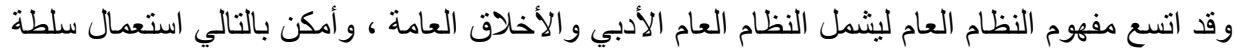

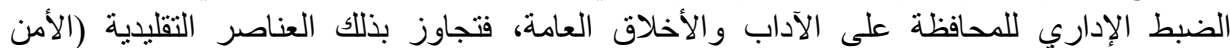

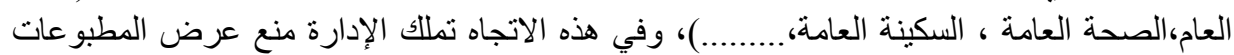

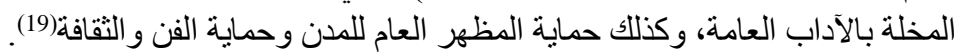

ويمثل النظام العام الجمالي أحد الأبعاد الحديثة للنظام العام، ويرجع الفضل في بلورته إلى الفقه الفرنسي

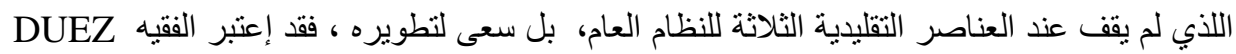

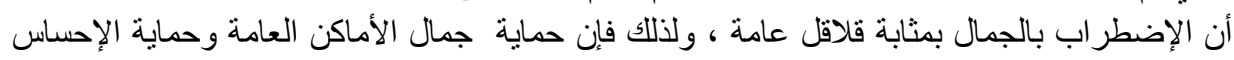

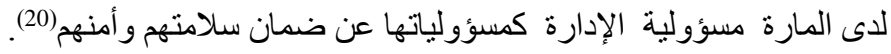

ومن جهته إعترف القضاء الإداري الفرنسي ومن ورائه المشرع بالجمال كهدف للقرار ات الإدارية من

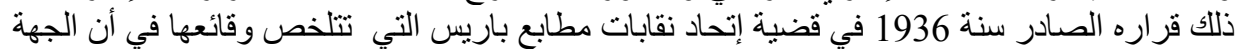

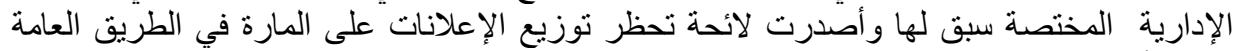

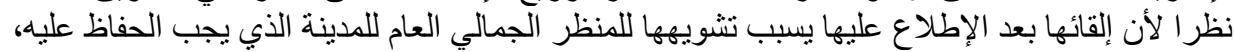

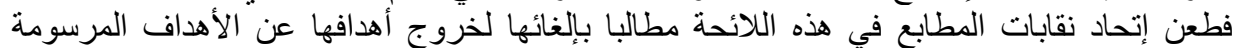

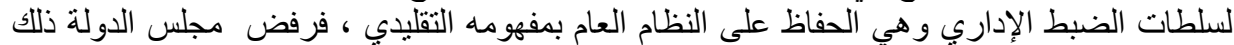
مؤكدا أن حماية الرونق يعتبر أيضا من أغراض اضل الضبط الإداري بوصفها إحدى عناصر النظام العام الغرلي 
الجديرة بالحماية وبذللك إستقر قضاء مجلس الدولة الفرنسي على مشروعية تدخل سلطات الضبط

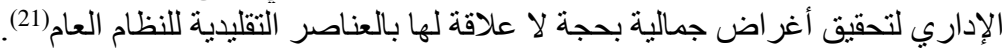

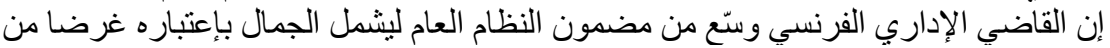

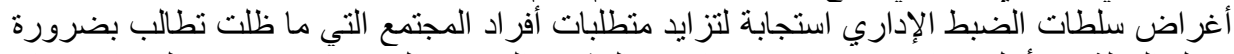

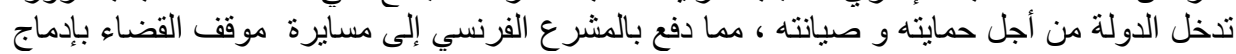

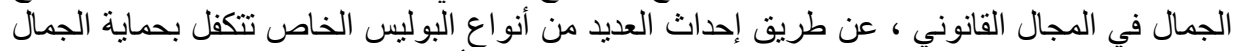

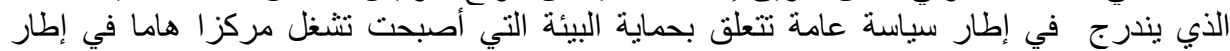
إنشغلات و إهنمامات الدولة.

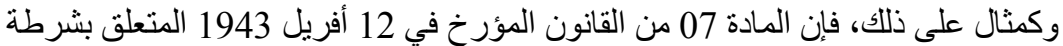

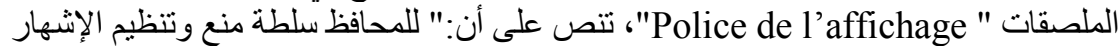

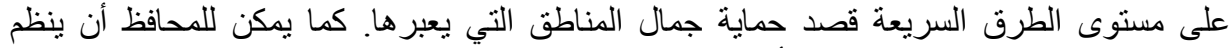

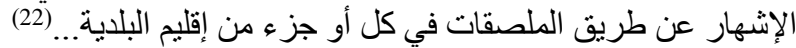

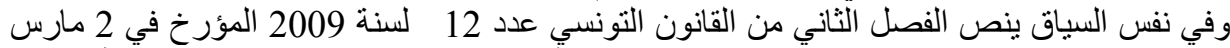

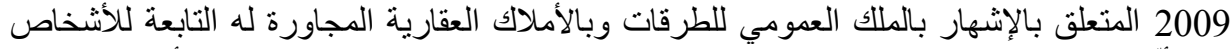

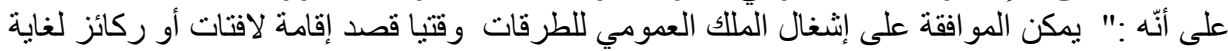

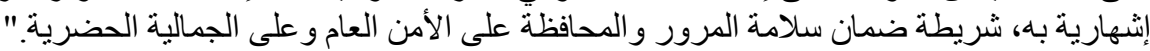

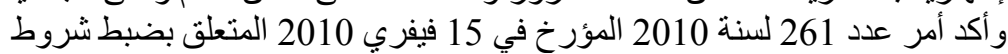

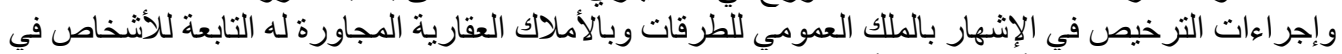

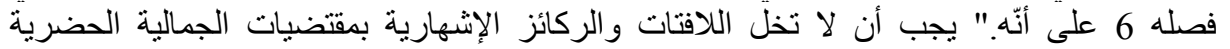

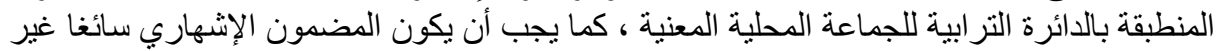

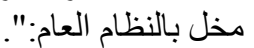

المبحث الثاني: الإشهار التجاري و حقوق الإنسان: - المان

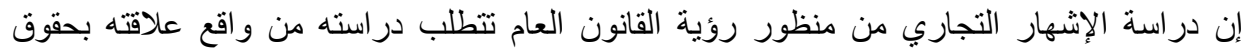

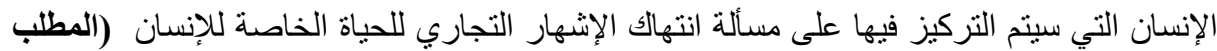

$$
\text { الأول)، بالإضافة إلى إستغلال المر أة في الإثهار التجاري (المطلب الثثاني). }
$$

المطلب الأول: إنتهاك الإشهار التجاري للحياة الخاصة للإنسان

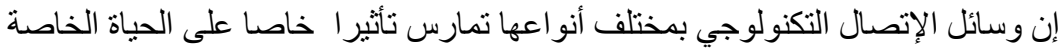

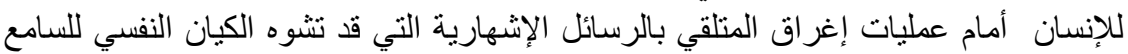

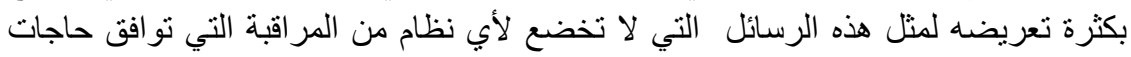

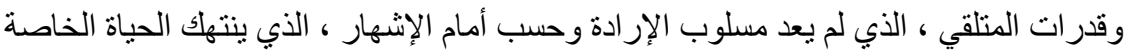

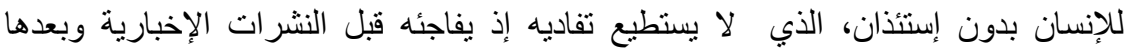

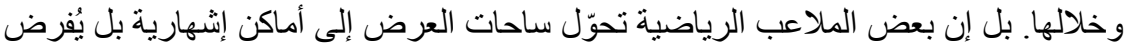

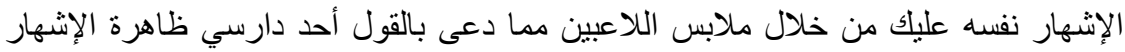

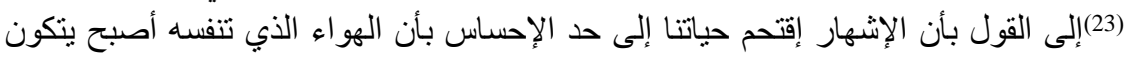

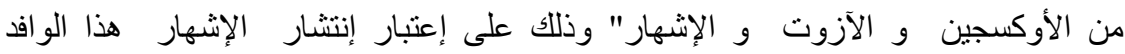

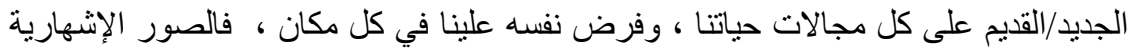


إحتلت كل الفضاءات ،فحيثما وليت وجهك تضرب عينك وسمعك إنثهارات، إذ كل الأماكن

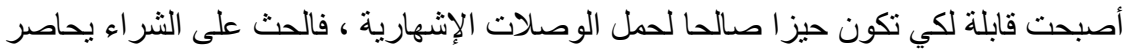

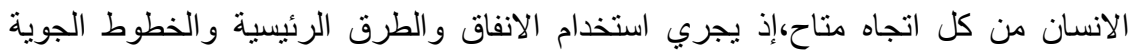

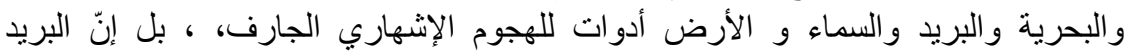

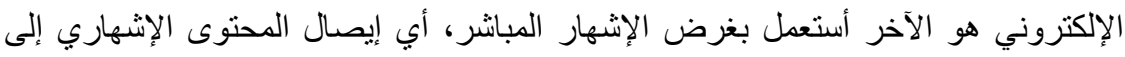

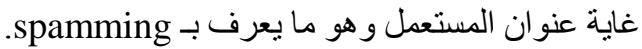

واستقرّ الرّابي على أنّ هذه الطّريقة لا يمكن أن تنّمّ إلاّ في إطار قانوني باعتبار أنّ البريد

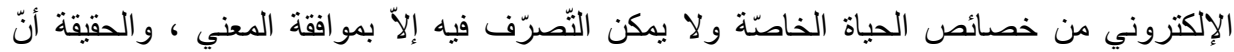

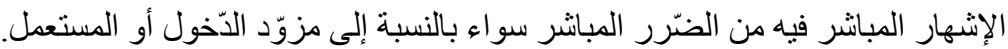

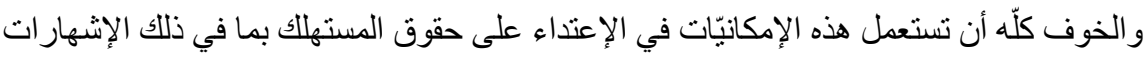

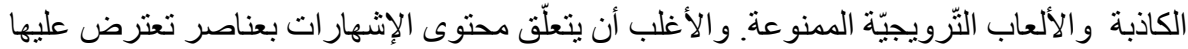

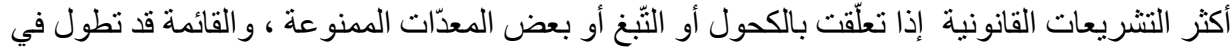

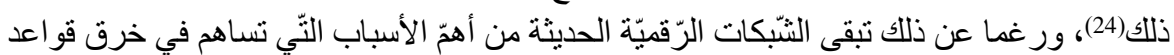

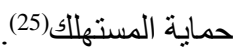

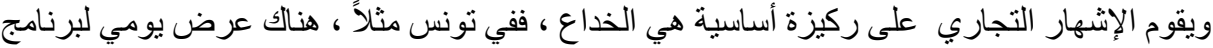

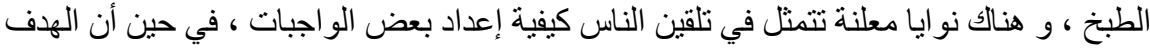

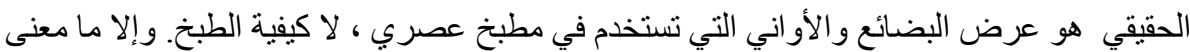

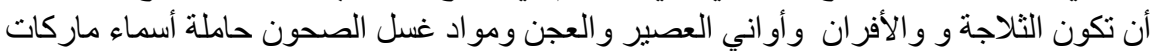

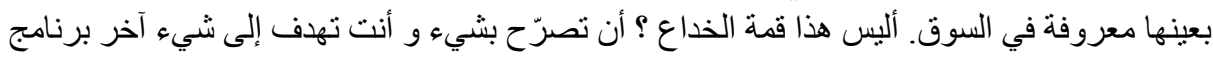

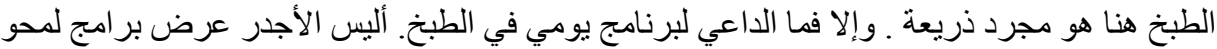

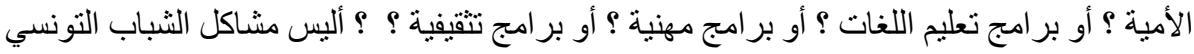

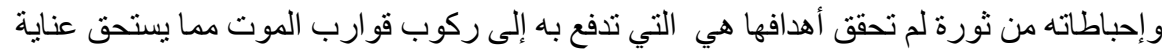
التلفاز

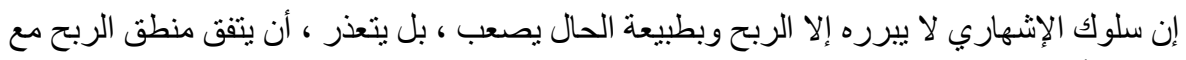

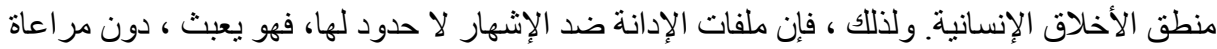

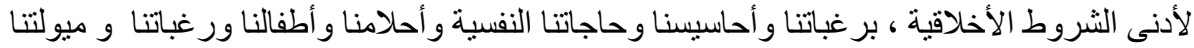

فالإشهار ذو بعد اقتصادي لا تخفي جو انبه من حيث تنشيط الحركة الاقتصادية، ولكن هذا

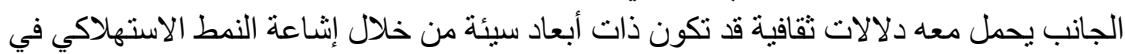

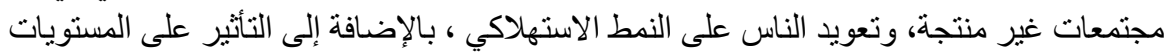

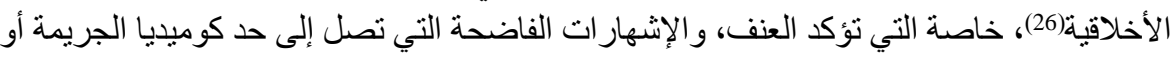

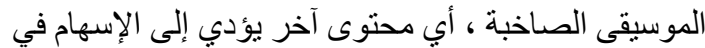

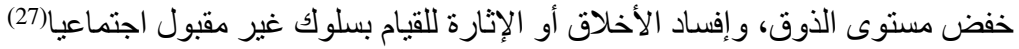
و كما يقول الكاتب"سعيد بنكر اد "فإن " ما يستهو ي الذات المستهلكة في المنتوج هي 


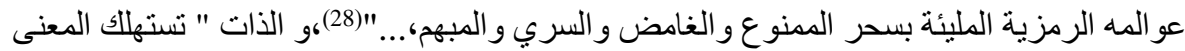

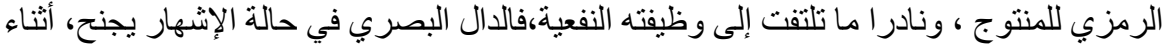

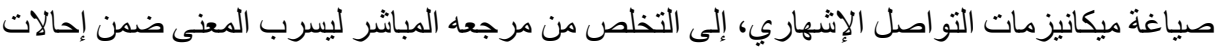

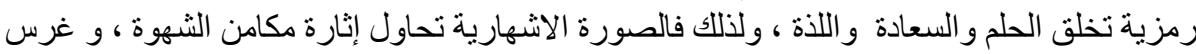

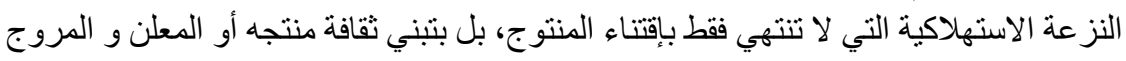

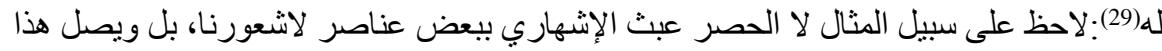

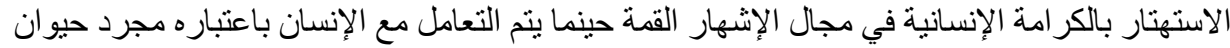

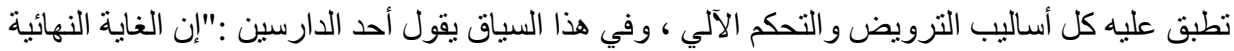

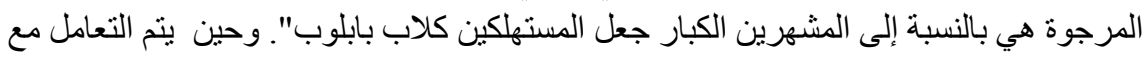

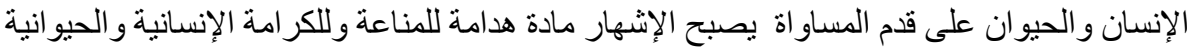

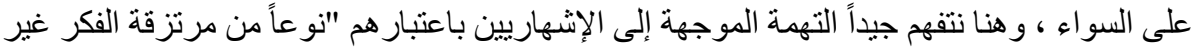

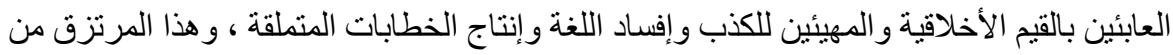

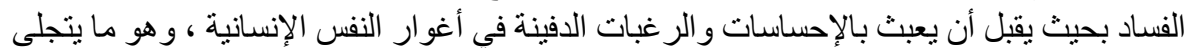
بالخصوص في إستغلال المرأة في الإشهار التجاري. المطلب الثاني : إستغلال المر أة في الإثهار التجاري

إن إستغلال صورة المرأة في الإنشهار التجاري ليس أمرًا وليد اليوم ، فمنذ القرن 19 بدأت صورة

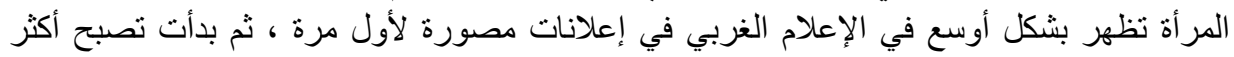

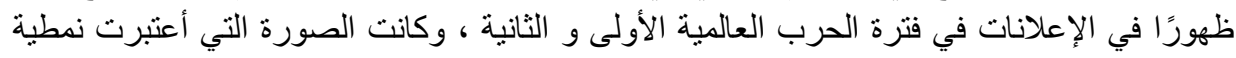

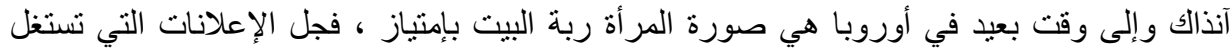

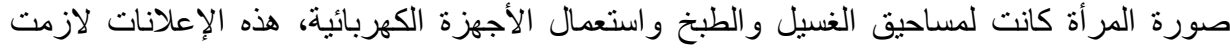

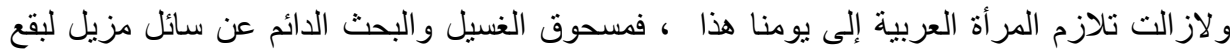

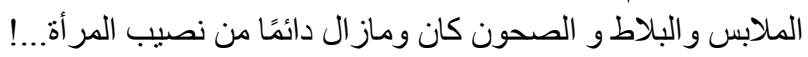

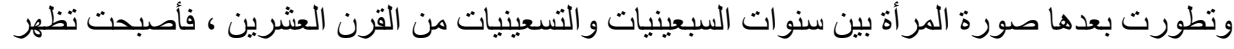

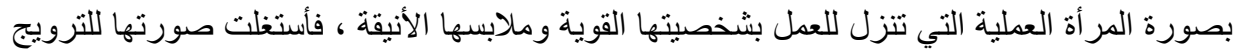

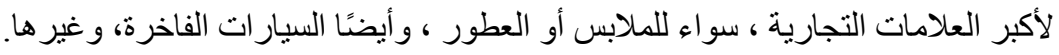

وفي العقد الأول من القرن الحالي اقتحمت بيوتتا من خلال القنوات الفضائية صورة نمطية للمرأة في

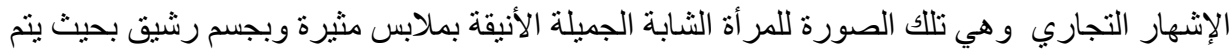

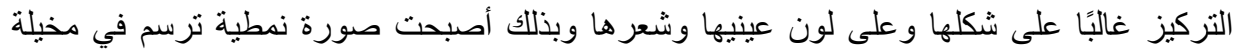

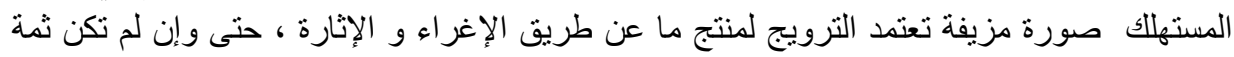

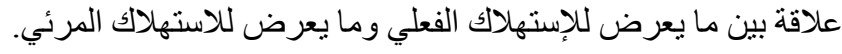
أن الصورة الإشهارية التي وظف المرأة توظيفا ميكانيكيا و مبرمجا تتسلل إلى ذهن المتلقي بخفة و

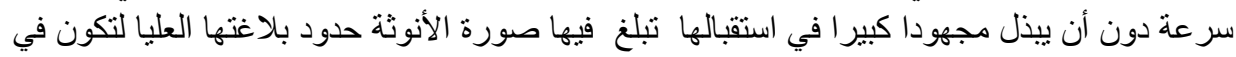




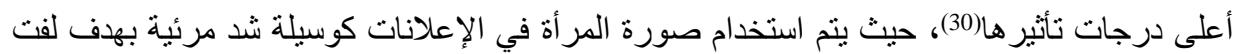

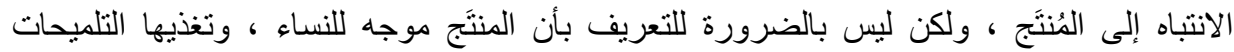
و الإيحاءات ـمن داخل الإشهار (31)مما ساهم في هدر إنسانية المر أة وكر امتها.

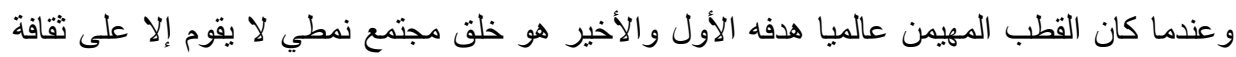

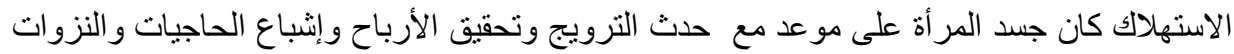

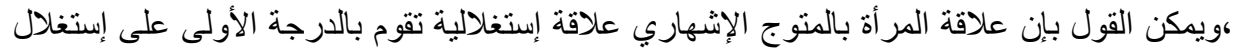

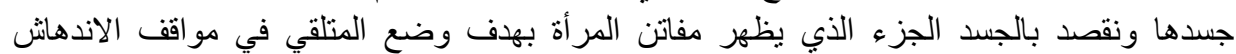

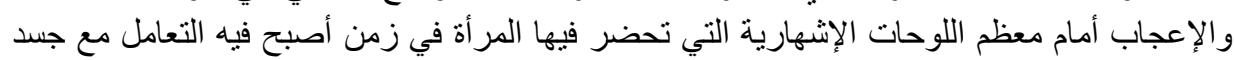

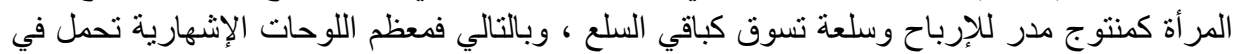

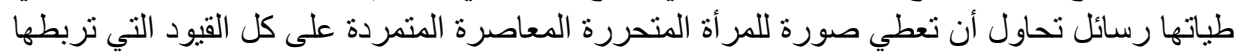

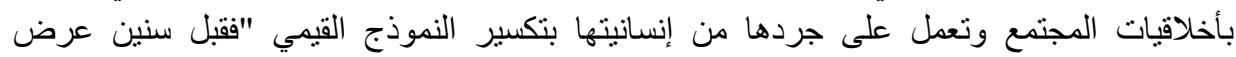

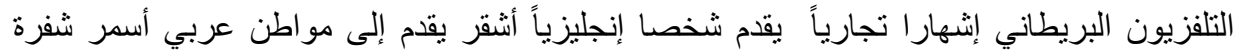

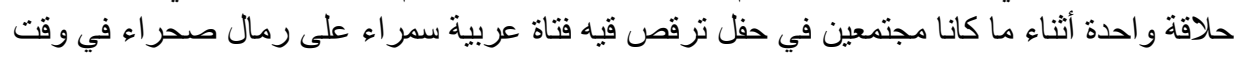

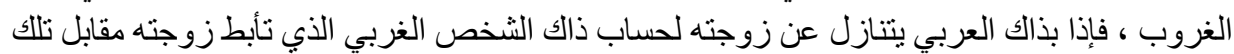

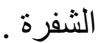

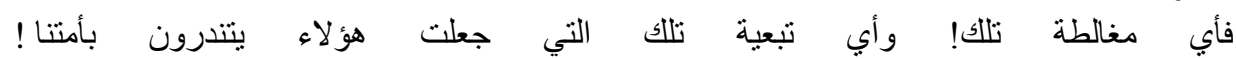

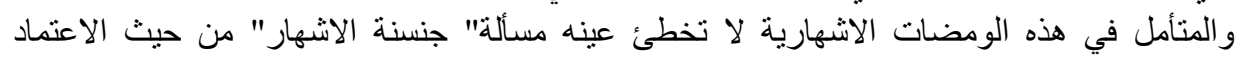

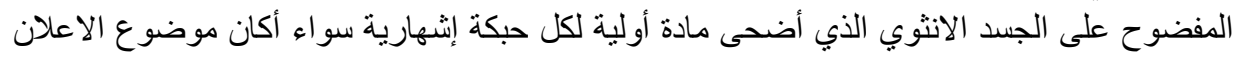

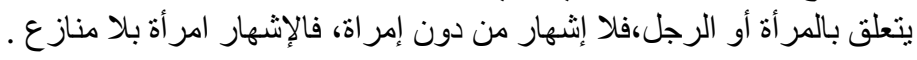

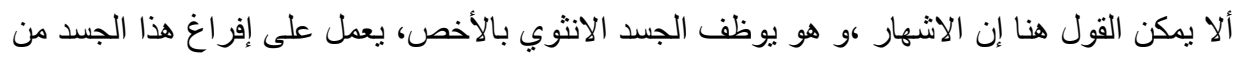

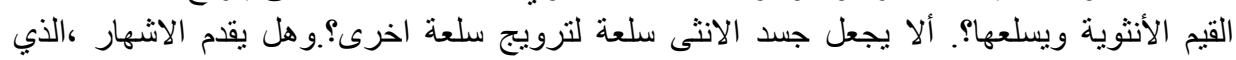

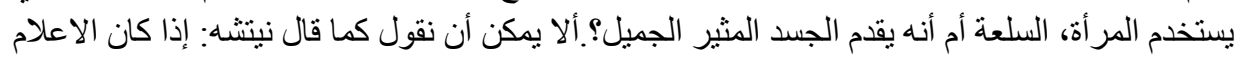

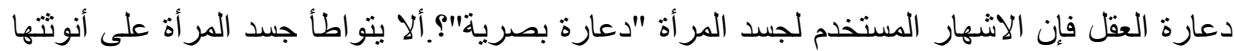

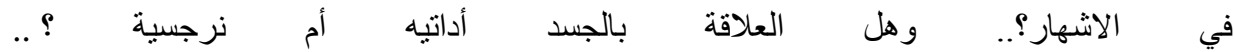

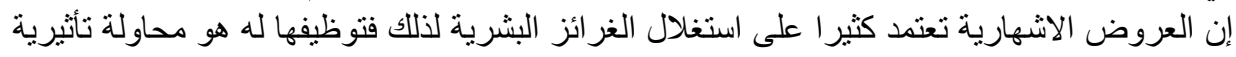

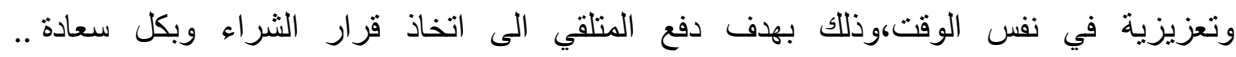

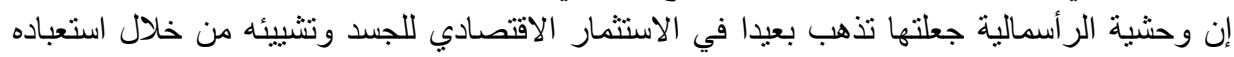

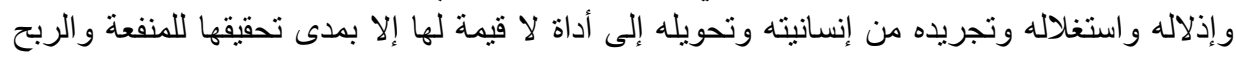

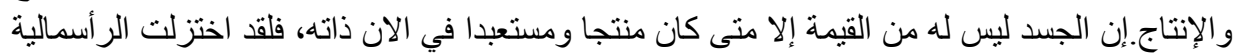

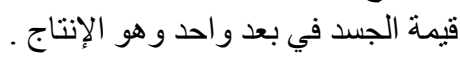

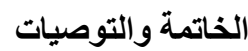

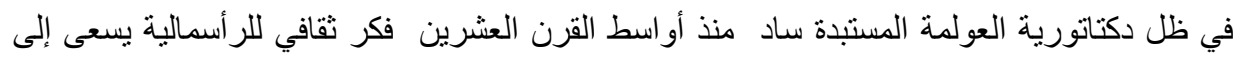

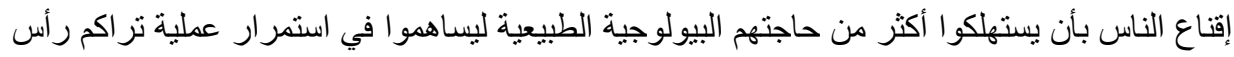
المال بغاية الربح الخاص ، و بكلمات أخرى للتأكد من أن النظام الرأسمالي العالمي لئهي مستمر للأبد. 
إن تحليل الخطاب الإنشاري تحليلا عميقا يمكنتا من نفي طابع الحياد و البراءة التي يتستر تحتها الاشهار

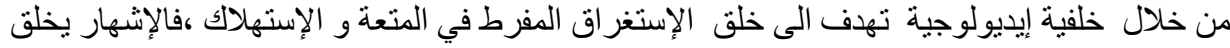

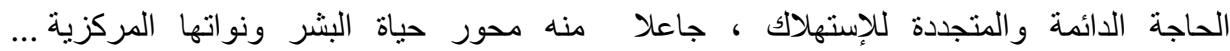

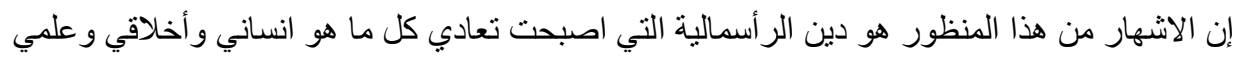

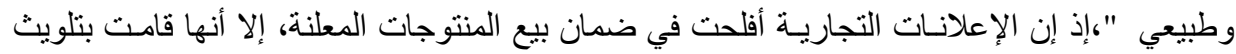

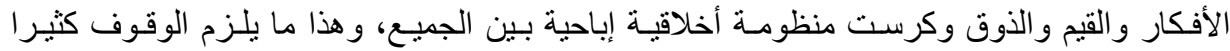

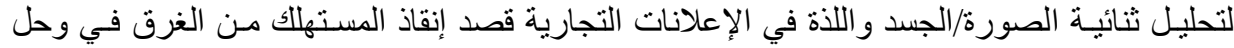
الصور الجنسية وتبيان أثرها على الوجدان و النفس و العقل.

إن الساعي الى الربح الأعمى، وهو يشغل كل الوسائل لتحقيق غايته ، و الثركات هي أصل هذا

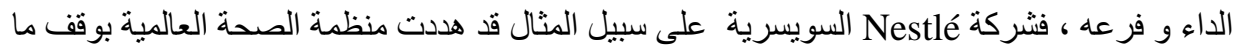

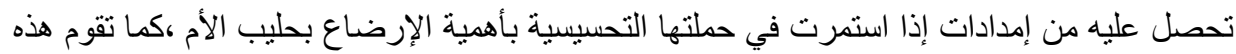

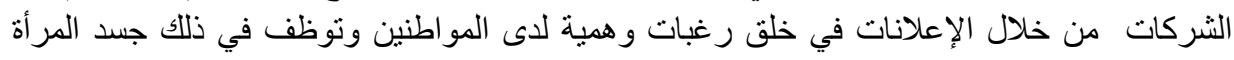

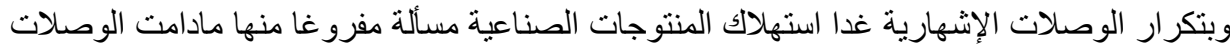

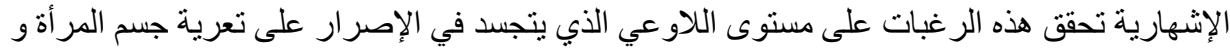

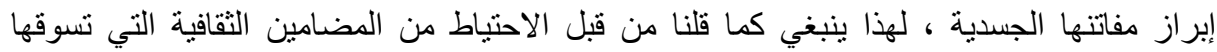

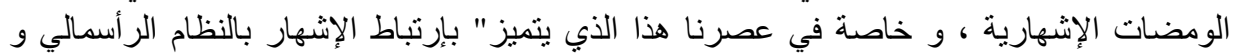

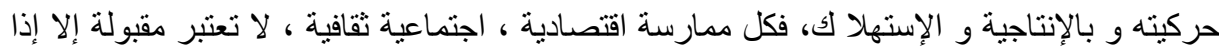

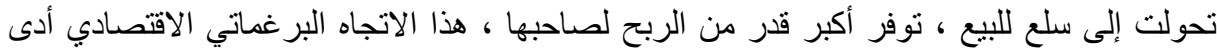

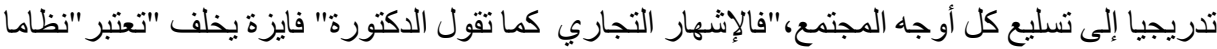

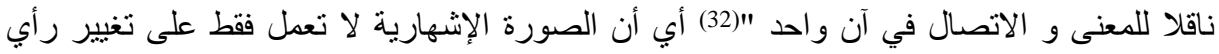

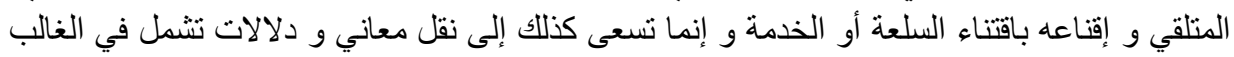

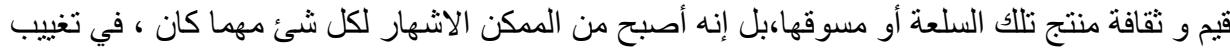

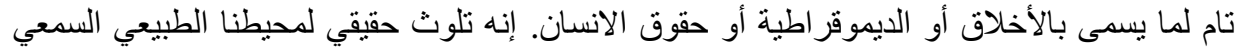

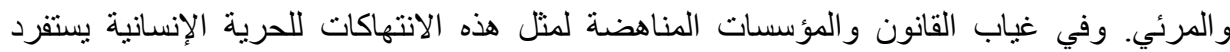

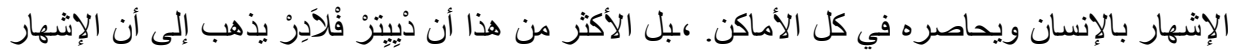

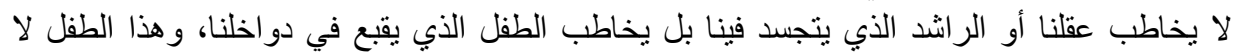

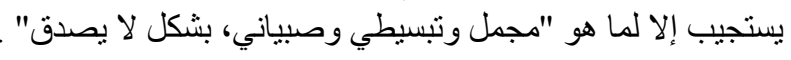

ولكل ما سبق ينبغي وضع حد لهذا الانجر اف من خلال خضوع اللوحات الإشهارية صورة كانت أم أم إمبات

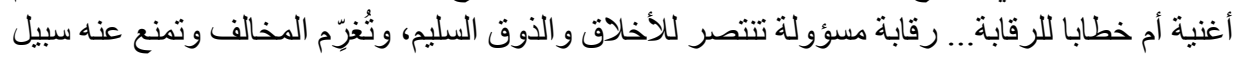

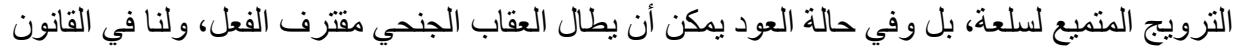

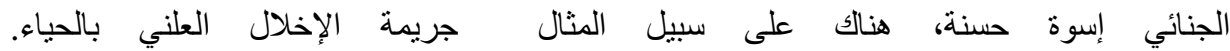


1- Salah Amamou : Le Manuel Permanent du Droit des Affaires Tunisien, Tunis, 1994, V 3 , p.1 .

2-Jacques lendrevie et Arnaud debaynast : publicitor, Ed Nº,Dalloz, p. 67.

3 - خنان شعبان : أثر الفو اصل الإشهارية التلفزيونية على عملية التلقي ، در اسة استطلاعية لجمهور

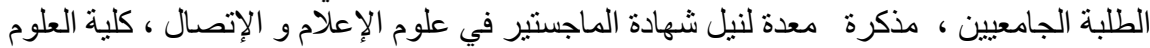

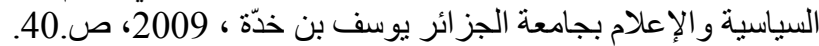

4 - Robert leduc :Rôle économique de la publicité in colloque : l'avenir de la publicité et le droit, actualités du droit de l'Enterprise, n ${ }^{\circ}$, Montpellier, 1976, p.14

5 - لمزيد التعقى في دراسة البعد الإقتصادي للإشهار راجع : فايزة يخلف : خصوصبية الإشهار

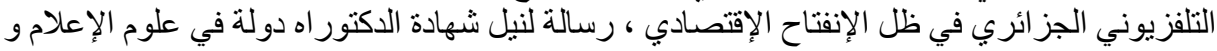

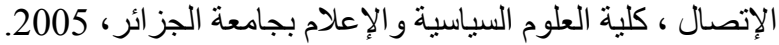

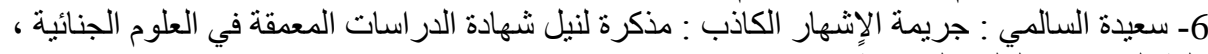

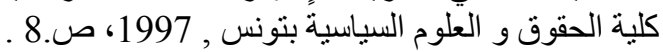

7 - منع الإشهار لبيع الأعضاء البشرية على أساس قانسانون 25 مارس 1991 المتعلق بأخذ الأعضاء

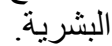

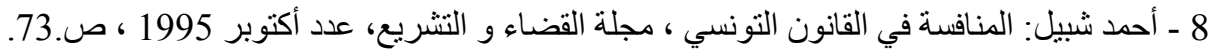

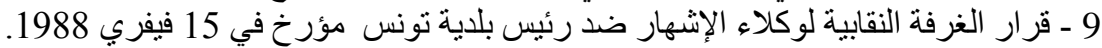

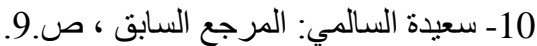

11 ـ طلعت همام: مائة سؤآ عن العلاقات العات العامة و الإعلان ، عمان ، دار المعارف ، 1984 ، ص,37

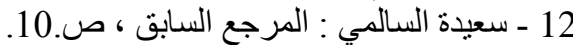

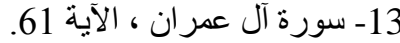

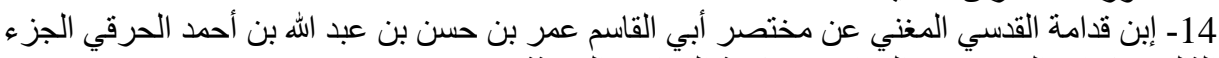

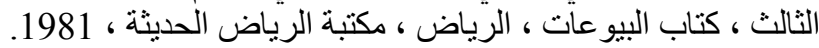

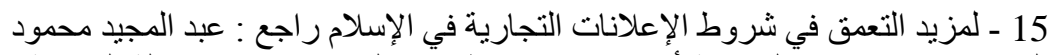

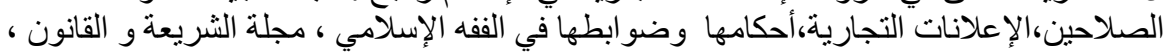

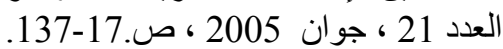
16 - المجتمع الإستهلاكي هو المجتمع الذي يكون فيه تأثير الثركات على الإستهلاك العامل الأساسي

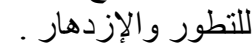

17- عبد الرزاق السنهوري :الوسيط في شرح القانون الجديد ، المجلد الأول ، مصادر الالتزام ،

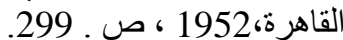

18 - هشام علي صادق وحفيظة السيد الحداد، دروس في القانون الدولي الخاص ، مطبعة الإنتصار،

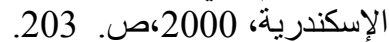

19 - علاء الدين عثي : مدخل القانون الإداري، ، ، دار الهذى للطباعة و النشر و التوزيع، عين مليلة -

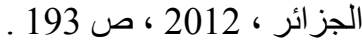

20 - محمود عاطف البنا: حدود سلطة الضبط الإداري ، مجلة القانون و الإقتصاد، العدد الرابع ،

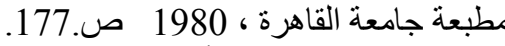
21- عادل السعيد محمد أبو الخير : الضبط الإداري و حدودهد ، مطابع الطويجي التجارية ، القاهرة ،

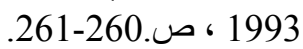




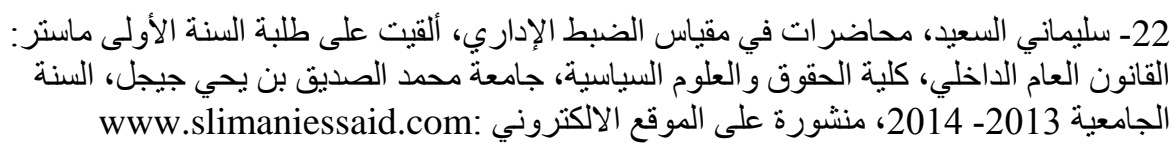

23-Sophie Baumel: La publicité trompeuse dans la jurisprudence, université Montpelier, 1998.

24-علي كحلون: لجريمة المعلوماتية وتوجهات محكمة التعقيب maitremahmoudyacoub.blogspot.com/2013/03/blog-post_2204.html

25- Elloumi abderraouf, la protection du consommateur dans le commerce électronique, DEA, faculté de droit de sfax 2001-2002.

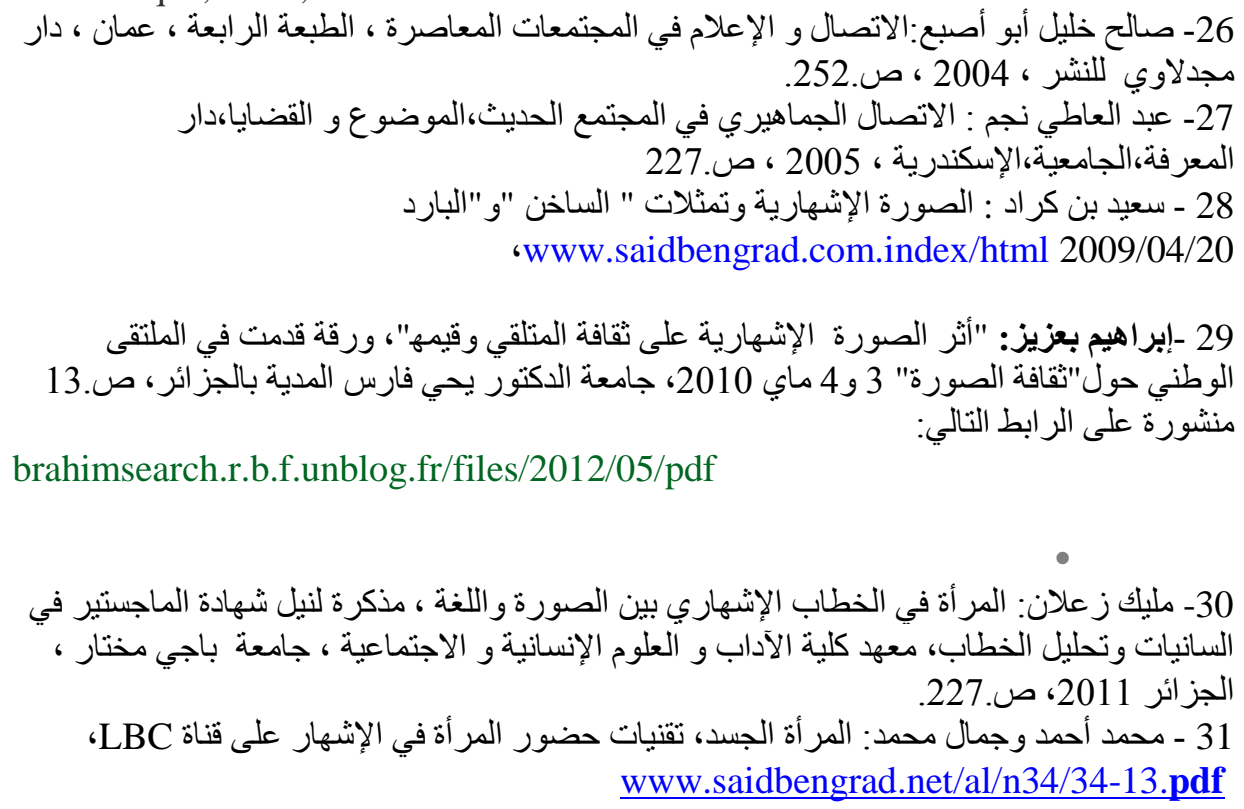

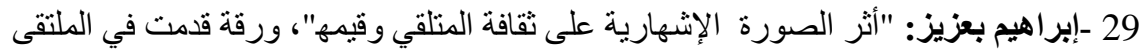

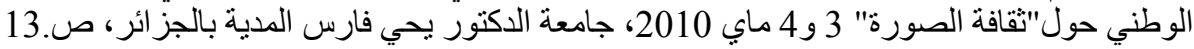
brahimsearch.r.b.f.unblog.fr/files/2012/05/pdf

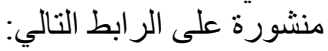

